\title{
Desigualdade de oportunidades educacionais na rede pública municipal do Rio de Janeiro: transição entre os segmentos do ensino fundamental*
}

\author{
ANA LORENA BRUEL \\ Universidade Federal do Rio de Janeiro \\ TIAGO LISBOA BARTHOLO \\ Universidade Federal do Rio de Janeiro
}

\section{INTRODUÇÃO}

Diversos avanços no campo educacional no Brasil são destacados em estudos nos últimos dez anos. Entre as principais conquistas, podemos citar a quase universalização do acesso ao ensino fundamental, o aumento das taxas de conclusão do ensino fundamental e médio e o aumento dos anos de escolaridade da população como os mais significativos (Veloso et al., 2009).

* Trabalho apresentado no Grupo de Trabalho Sociologia da Educação (GT-14), na 34a Reunião Anual da ANPEd, realizada de 2 a 5 de outubro de 2011, em Natal-RN. Este estudo foi realizado com financiamento da Coordenação de Aperfeiçoamento de Pessoal de Nível Superior (CAPES) e Instituto Nacional de Estudos e Pesquisas Educacionais Anísio Teixeira (INEP). Os autores agradecem a disponibilização do banco de dados da Secretaria Municipal de Educação da cidade do Rio de Janeiro, sem o qual este estudo não seria possível. Agradecemos a inestimável contribuição do professor doutor Marcio da Costa e da professora doutora Mariane Koslinski na análise dos dados e elaboração do artigo. 
Com a tendência à oferta de vagas em quantidade suficiente para atender à demanda de acesso inicial ao ensino fundamental, o debate foi deslocado para três novos temas: 1) o acesso aos diferentes níveis de escolaridade; 2) a permanência dos estudantes ao longo do processo de escolarização com vistas à conclusão da educação básica; 3) a qualidade do ensino ofertado principalmente na rede pública ${ }^{1}$ e o debate sobre a equidade entre estabelecimentos.

Diversamente do que o senso comum defende, a diferença de qualidade entre as escolas vai muito além da dicotomia entre escola pública e escola privada - com vantagem para o segundo modelo. Políticas voltadas para a melhoria do ensino na rede pública foram adotadas e atuam em direções complementares: algumas buscam redistribuir os investimentos em educação assegurando um mínimo de gasto anual por aluno; ${ }^{2}$ outras objetivam reestruturar o atual funcionamento da gestão educacional, tornando o sistema mais eficiente; há também programas de descentralização implementados como estratégia para a democratização do acesso à educação básica.

Mais recentemente, observamos um aumento dos debates sobre os impactos de políticas educacionais que estimulam mecanismos competitivos entre as escolas, com o objetivo de melhorar o sistema público de ensino. Estudos desse campo estão ancorados em pesquisas voltadas à diferenciação do efeito das escolas (school matters, school effects) e à efetividade escolar (school effectiveness).

Dados mais recentes obtidos em avaliações nacionais com testes padronizados sobre o desempenho de alunos em escolas públicas têm iluminado novas questões de pesquisa relacionadas a dois pontos centrais. A primeira questão destaca a baixa qualidade do ensino ou, em outros termos, o baixo aprendizado dos alunos. A novidade não é a percepção da baixa qualidade do ensino ofertado, e sim a disponibilidade de uma medida objetiva que possibilita comparações entre instituições, redes e sistemas que compõem o quadro nacional. Isso permitiu, por exemplo, a construção de metas e planos de ação para a proposição de mudanças. A segunda questão é menos conhecida e mais relevante para o problema de pesquisa deste artigo, a saber, a grande heterogeneidade entre escolas da mesma rede.

Essa grande diferenciação entre as escolas evidencia uma hierarquização do sistema público. Temos, assim, escolas de maior e menor prestígio, com desempenhos diferentes, dentro da mesma rede de ensino. Esse dado gerou uma série de investigações sobre o prestígio escolar e a composição dos estabelecimentos escolares. Boa parte da literatura no campo da sociologia da educação, desde a década de 1950, relaciona

1 Dados recentes do INEP indicam que a rede pública no Brasil é responsável por 89\% das matrículas na educação básica. Disponível em: <http://www.inep.gov.br/imprensa/ noticias/censo/escolar/news00_14.htm>. Acesso em: 1 out. 2010.

2 Podem ser citados como referências os programas do governo federal: Fundo de $\mathrm{Ma}-$ nutenção e Desenvolvimento do Ensino Fundamental e de Valorização do Magistério (FUNDEF), ampliado para o Fundo de Manutenção e Desenvolvimento da Educação Básica e de Valorização dos Profissionais da Educação (FUNDEB), que objetivavam estabelecer um valor mínimo de gasto por aluno por ano no país. 
desempenho escolar com composição escolar diferenciada. Em outros termos, escolas com bons resultados em geral são escolas mais seletivas (Brooke; Soares, 2008).

No Brasil, o cenário de disputa das famílias pelas melhores escolas e das escolas por mais alunos era razoavelmente conhecido no sistema privado de ensino, porém, mais recentemente, estudos indicam processo semelhante de competição na rede pública (Alves; Soares, 2007; Medeiros, 2011). De modo geral, os trabalhos que analisaram as hierarquias intraescolare $\mathrm{s}^{3}$ e entre instituições da rede pública indicam que: 1) a percepção das famílias, dos professores e gestores sobre a qualidade das escolas é distinta, esse mecanismo cria uma hierarquização das escolas da mesma rede; 2) a percepção dos professores e gestores sobre o público que frequenta as escolas é distinta, ou seja, há uma rotulação dos alunos (Rist, 1977), identificando-se aqueles mais ou menos aptos para o trabalho escolar. Esse cenário apresenta um campo fértil de análise para estudos sobre o tema das desigualdades de distribuição das oportunidades educacionais.

No presente artigo, analisamos o período de transição entre o primeiro e o segundo segmento do ensino fundamental, em escolas públicas "comuns", ${ }^{4}$ da rede municipal da cidade do Rio de Janeiro, visando identificar fatores que condicionam chance de acesso a estabelecimentos que obtiveram bons resultados em avaliações nacionais.

Trabalhamos com a hipótese de que a seleção de alunos pelos estabelecimentos escolares não ocorre de forma aleatória e apresenta impacto no aumento das desigualdades de oportunidades educacionais. $\mathrm{O}$ foco na transição entre o primeiro e o segundo segmento do ensino fundamental parece uma investigação promissora para se observar os mecanismos de seleção estabelecidos pelo lado da oferta, uma vez que na cidade do Rio de Janeiro parte das escolas públicas municipais atende somente a um desses segmentos e, portanto, observa-se um intenso fluxo de alunos na transição entre os anos iniciais e finais do ensino fundamental.

Para tratar das questões aqui propostas, na primeira seção discutimos o conceito de quase mercado escolar, sublinhando os principais mecanismos que caracterizam seu funcionamento em contextos em que políticas para incentivá-los foram formal-

3 As hierarquias intraescolares são aquelas criadas pela separação dos alunos por turmas, a partir de critérios de níveis de habilidade, ou ainda a separação dos alunos nos diferentes turnos - manhã, tarde e noite. Acreditamos que esse processo de homogeneização do alunado é muito intenso, pois não depende de mecanismos burocráticos externos à escola para ocorrer, ou seja, a decisão se o aluno irá mudar de turma ou turno depende basicamente dos atores presentes nos estabelecimentos escolares - professores e diretores.

4 Acrescemos o adjetivo "comuns" sem qualquer sentido pejorativo, apenas para diferenciar as escolas públicas municipais daquelas federais ou das pouquíssimas estaduais (colégios de aplicação ou escolas técnicas), que dispõem de recursos diferenciados e/ou formas de seleção explícitas, por desempenho. Tais unidades apresentam composição de alunado que não poderia ser tomada como equivalente à das escolas que aqui designamos "comuns". 
mente instituídas. Em seguida, tratamos da relevância desses elementos conceituais para compreender o contexto brasileiro, e mais especificamente na cidade do Rio de Janeiro. Por fim, trazemos algumas evidências sobre os padrões de transferência de alunos de ensino fundamental a partir de uma primeira exploração da base de dados longitudinal de estudantes da Secretaria Municipal de Educação (SME).

\section{QUASE MERCADOS EDUCACIONAIS E QUASE MERCADOS OCULTOS}

Buscando elementos conceituais que nos auxiliassem na compreensão de nosso objeto, encontramos um crescente número de trabalhos voltados à temática do chamado quase mercado e seus impactos sobre desigualdades e estratificação escolar. As discussões foram impulsionadas pelas experiências de países que adotaram políticas que pretendiam incentivar a escolha de estabelecimentos escolares e induzir a competição entre escolas, instituindo sistemas de consequências (bigh-stakes) ou de responsabilização (accountability).

Tais medidas fazem parte de um grupo de políticas conhecidas como reformas pós-Estado de bem-estar, que incentivam a introdução de elementos de mercado. Recorrem a artifícios "como o estímulo à escolha do consumidor, a publicação de indicadores de desempenho e recompensas financeiras pelo sucesso" (Gorard; Taylor; Fitz, 2003, p. 3, tradução nossa), com o intuito de melhorar a qualidade de serviços públicos. No que diz respeito às políticas educacionais, proponentes de reformas em direção aos quase mercados escolares ${ }^{5}$ partem de alguns pressupostos sobre o efeito da escolha e da competição sobre a melhoria da qualidade da educação. $\mathrm{O}$ principal argumento para a implementação das políticas de escolha escolar nas reformas dos sistemas educacionais enfatiza a possibilidade de promoção de três dimensões educacionais: autonomia, inovação e responsabilização/accountability dos estabelecimentos de ensino (Berends; Zottola, 2009).

As pesquisas sobre os impactos das políticas de escolha da escola pelos pais analisam dois aspectos complementares do mesmo processo: 1) o lado da demanda contemplando os critérios elaborados pelas famílias para orientar sua tomada de decisão; e 2) o lado da oferta - considerando as estratégias utilizadas pelas escolas e pelos diferentes níveis da administração do sistema de ensino para atrair e selecionar estudantes que buscam uma matrícula.

Parte das análises sugere que o poder de escolha/seleção do alunado pelas escolas é um elemento que pode gerar segmentação entre as unidades da mesma rede e diminuir a equidade dos sistemas educacionais (West; Pennell, 2002).

5 Para Le Grand (1991), são “quase” mercados, pois incentivam a competição entre empreendimentos produtivos, em contraposição ao monopólio estatal. Entretanto, não buscam necessariamente maximizar lucros e os consumidores não utilizam dinheiro, mas vouchers ou outros recursos para consumir um serviço específico. 
Pelo lado da demanda, os quase mercados educacionais funcionam pela concessão e incentivo à livre escolha por parte dos pais entre uma lista de escolas. Opõem-se, por exemplo, a uma restrição da matrícula com base geográfica. A maior liberdade de escolha permitiria maior interação entre casa e escola, maior abertura para a demanda dos pais e, consequentemente, maior diversificação das escolas. Em uma perspectiva de escolha racional, os pais são vistos como consumidores que buscam maximizar a utilidade de suas preferências. Portanto, informação, escolhas disponíveis e análise custo-benefício seriam elementos importantes para o processo decisório dos pais, que supostamente agem em um mercado escolar aberto, justo e não tendencioso ${ }^{6}$ (Berends; Zottola, 2009).

Haveria, tendencialmente, um processo de ajuste da oferta, incremento de sua qualidade (capacidade competitiva), pelo fato de não mais se fazerem presentes os mecanismos de proteção típicos dos arranjos consolidados no que se convencionou denominar "estados do bem-estar". Estudantes seriam disputados, segundo essa lógica, com base em uma oferta escolar forçada a elevar sua capacidade de atração. Assim, a partir da sinalização emitida por sistemas centralizados de avaliação educacional externa, a oferta tenderia a elevar sua qualidade pelo efeito agregado da competição por clientes. Diante da introdução de mecanismos de distribuição de recursos por estudantes, por meio de sistema de vouchers, as escolas e educadores teriam oportunidade e motivação para experimentar novas estratégias organizacionais e instrucionais para melhorar os resultados de seus alunos e para atrair mais "clientes".

Entretanto, estudos que avaliam a introdução de políticas de quase mercado e de escolha de estabelecimentos escolares mostram possíveis efeitos negativos por elas trazidos, como, por exemplo, o aumento na estratificação escolar com a homogeneização do alunado em termos da composição socioeconômica e/ou racial. Mesmo entre os defensores de tais políticas, há o reconhecimento de suas fraquezas, das imperfeições e das externalidades negativas que podem promover.

A criação dos quase mercados escolares foi seguida de estudos avaliativos que buscaram identificar os efeitos das políticas de escolha escolar em países como a Inglaterra, Estados Unidos da América (EUA), Nova Zelândia, Chile, entre outros (Berends; Zottola, 2009; Glenn, 2009; Thrupp, 2007; West; Pennell, 2002). Os resultados são contrastantes e não indicam um consenso sobre os possíveis benefícios ou malefícios das políticas de escolha escolar, em parte porque as regras e os modelos de intervenção foram distintos nos países, gerando resultados diferentes. Em contraposição, as reações dos atores que integram os sistemas educacionais perante as novas regras também variam, o que pode gerar efeitos perversos não previstos.

6 A publicação de rankings das escolas com base em testes padronizados, tais como as "School Performance Tables", no contexto do Reino Unido, seria um exemplo de mecanismos capazes de promover um quase mercado com tais características (Gorard; Taylor; Fitz, 2003). 
Tais efeitos devem ser foco de análises futuras, uma vez que podem, em alguns casos, anular possíveis resultados positivos gerados inicialmente pela nova política.

Entre as pesquisas realizadas neste campo, podemos citar os estudos desenvolvidos por Glenn (2009) e Thrupp (2007), que analisaram contextos distintos com políticas de escolha escolar, respectivamente nos EUA e na Nova Zelândia, por perspectivas bastante próximas, que defendem a importância do papel do poder público na regulação dos quase mercados escolares. Destacam que a simples criação do quase mercado pode se tornar mais uma causa para a segregação e a desigualdade escolar, aumentando os desequilibrios já existentes nos sistemas escolares. Os autores observaram que, em ambos os países, as elites locais se adaptaram com maior agilidade às novas regras de admissão, bloqueando parcialmente o acesso dos filhos das famílias menos favorecidas a oportunidades escolares vantajosas. ${ }^{7}$ Thrupp (2007) sugere que os gestores de política pública criem formas de financiamento com mecanismos compensatórios, ou seja, maiores incentivos para as escolas que receberem os alunos "menos desejados".

Alguns estudos argumentam que a maior liberdade de escolha de estabelecimentos escolares não promove, necessariamente, maior eficiência das escolas e maior igualdade no sistema escolar. Isso porque, no lado da demanda, os pais levariam em conta diversos critérios, além do desempenho da escola, na hora de realizar a escolha. Também consideram em sua escolha o perfil do alunado que frequenta as escolas (Berends; Zottola, 2009; Holme, 2002). Além disso, pais que pertencem a diferentes grupos sociais não disporiam dos mesmos recursos (informações, capacidade de interpretar informações e redes sociais) para realizar suas escolhas (Holme, 2002).

Como reação a essas escolhas, as escolas não adotariam ações inovadoras para melhorar a sua qualidade, mas tentariam atrair famílias de maior status socioeconômico. Outras críticas mostram que reformas, como o Educational Reform Act (ERA 88), aprovado em 1988, no Reino Unido, permitiram maior autonomia das escolas na admissão dos alunos e abriram espaço para a adoção de procedimentos para alcançar um influxo de alunos mais favorável, evitando alunos "difíceis de ensinar" (West, 2006; West; Pennell, 2002). Cabe ressaltar que os mecanismos de seleção presentes nas escolas podem produzir efeitos de ampliação das desigualdades.

Os achados mais clássicos da sociologia da educação indicam que o desempenho dos alunos está diretamente relacionado ao seu perfil socioeconômico. Dessa forma, as políticas de escolha escolar, caso queiram aumentar a qualidade e equidade do sistema de ensino, devem limitar o poder de seleção das escolas, sob risco de as medidas competitivas potencializarem esse efeito seletivo. Isso ocorre porque as escolas reconhecidas como melhores tendem a receber uma demanda maior do que o número de vagas ofertado, o que permite a seleção dos alunos. Esse potencial de seleção determinaria em grande parte seu sucesso no processo de ensino/aprendizagem.

7 A maioria dos estudos sobre impactos das políticas de school choice parte de uma premissa individualista, ou seja, os desejos dos atores explicam suas escolhas em relação à escola. Esquecem, porém, que a escolha de um estudante limita a opção de escolha dos outros (Yair, 1996). 
O debate acumulado sobre competição de alunos por melhores escolas e a restrição do poder de seleção das escolas nos ajudam a pensar a especificidade das desigualdades de oportunidades educacionais presentes na rede pública municipal da cidade do Rio de Janeiro. Como bem destaca Coleman (1992, p. 261, tradução nossa), a ausência de critérios objetivos de diferenciação entre os estabelecimentos escolares não evita a hierarquização e a posterior seleção das famílias.

A estratificação em meio às escolas elementares e médias não está ausente, simplesmente porque a escolha não é permitida; ela se faz presente ao extremo e de uma forma que a priva dos incentivos trazidos por sistemas de estratificação, em seu melhor.

No contexto brasileiro, não existem políticas que explicitamente incentivem a livre escolha de instituições escolares. Ao contrário, em vários casos, as redes públicas municipais e/ou estaduais limitam tal escolha ou definem a priori os estabelecimentos escolares valendo-se de procedimentos de matrícula atrelados ao local de moradia dos alunos. Além disso, apesar do desenvolvimento de sistemas de avaliação e a disseminação de dados de desempenho das escolas em provas padronizadas, são poucos os programas estaduais e municipais que usam sistemas de consequências para responsabilizar e/ou promover competição entre as escolas.

Zanten (2009) observa que, por exemplo, na Bélgica, onde parecem prevalecer valores mais simpáticos ao mercado competitivo, a escolha escolar se exerce mais facilmente. Já, na França, com princípios igualitaristas mais arraigados, a competição/escolha ocorre de forma mais oculta, recorrendo-se mais a subterfúgios e sendo mais provável algum deslocamento para o interior das escolas, afetando a organização de turmas. ${ }^{8}$ Esse argumento fortalece nossa percepção de que a competição por escolas é razoavelmente independente de qualquer iniciativa política que venha a estimulá-la.

De forma similar, Yair (1996) observa, no contexto de Israel, a competição por escolas, mesmo na ausência de políticas que promovam a escolha da instituição escolar. O autor propõe a "ecologia do mercado" como conceito básico para compreender o trânsito de alunos entre escolas. Ele pensa em um sistema integrado em que um tipo de escola permite a existência de outro: escolas de maior seletividade dependem de outras que recebam os alunos que são delas expelidos. Em suma, conforme a tese de Yair (1996), estudantes competem por escolas, mas escolas não apenas competem, como também colaboram na divisão dos estudantes. Ao final, a ecologia do mercado escolar pode impedir ou, ao menos, limitar severamente a escolha "livre" e o mercado "livre". Sobretudo, pode tornar mais severos os já conhecidos mecanismos de reprodução da estratificação social manifestos nos sistemas de ensino. A ideia de

8 A autora relata que na França, apesar de desaconselhada ou proibida, a prática da organização intraescolar por grupos de habilidade é disseminada, à revelia das autoridades escolares. Já em outros países, como a Hungria, ela é instituída. 
uma "ecologia", compondo como que um sistema de vasos comunicantes, parece-nos valiosa para compreender contextos, como o do Rio de Janeiro, em que não se observa exatamente competição das escolas estudadas por alunos, considerando o pleno atendimento da população no ensino fundamental. $\mathrm{O}$ quase mercado funcionaria, assim, principalmente pelo lado da demanda e pelas barreiras seletivas interpostas por algumas escolas, sem incentivos financeiros associados.

A pesquisa de Franck Poupeau e Jean-Christophe François (2008), sobre mobilidade dos alunos entre escolas parisienses de centro e periferia, apresenta interessantes elementos de reflexão sobre a movimentação dos estudantes no interior do sistema de ensino público e a produção de desigualdades. Suas análises indicam que as escolas se situam em espaços de concorrência, caracterizados como hierárquicos e desigualmente acessíveis. Seus resultados sugerem que a mobilidade pode ser entendida como capital na medida em que abre oportunidades que não estariam presentes sem ela, quando se trata do acesso a escolas de prestígio. Tendo em vista que seria impossível garantir que todos os alunos pudessem se matricular em escolas de prestígio, essa prática contribui para o acirramento das desigualdades de oportunidade de acesso à educação de qualidade, já que é um comportamento mais presente nos grupos sociais favorecidos.

Em outros trabalhos anteriores que focalizaram o contexto da cidade do Rio de Janeiro, também observamos, mesmo na ausência de políticas explícitas que incentivassem a escolha de instituições escolares e diante das escassas políticas de consequências, a disputa por escolas públicas de alto prestígio e certas ações das escolas perante essa disputa. Pelo lado da demanda, observamos que os pais utilizam sinais de hierarquização para classificar as escolas públicas na busca por vagas para seus filhos. Entretanto, tais classificações não utilizam valores oferecidos pelos sistemas de avaliação já instituídos. São, em geral, baseadas em percepções sobre a organização da escola e a composição do alunado, elaboradas pelos pais com base em suas redes sociais, entre outros fatores (Costa; Koslinski, no prelo; Costa; Rosistolato; Prado, no prelo). Em contrapartida, as escolas e/ou as burocracias escolares e de nível intermediário da administração dos sistemas educacionais não são meros reagentes à demanda. Ao contrário do que preconizam as prescrições mais ortodoxas, elas participam de forma ativa, moldando a oferta e limitando as possibilidades de escolha (Costa; Koslinski, no prelo; Costa et al., 2010).

Isto é, mesmo na quase ausência de políticas que introduzam mecanismos de mercado, observamos a constituição de um quase mercado oculto exercendo impacto na formação de hierarquias observadas no interior das redes públicas de ensino compostas por escolas "comuns", que atendem à imensa maioria da população brasileira e, em especial, concentram suas parcelas mais pobres (Costa, 2008; Costa; Koslinski, no prelo).

Como vimos anteriormente, no caso dos quase mercados instituídos, as escolas utilizam mecanismos de seleção de alunos para aumentar sua reputação/ desempenho e consequentemente angariar mais financiamento a partir dos recursos proporcionados pela maior quantidade de alunos atraídos. 
No contexto estudado, caracterizado pelo funcionamento de um quase mercado oculto, a motivação das escolas de maior prestígio para selecionar alguns alunos e impor barreiras para a entrada de outros não provém de recompensa em recursos financeiros, mas da intenção de se manter certo "clima escolar" ordenado, facilitar o trabalho interno, preservar sua imagem e garantir certo orgulho de pertencimento a uma coletividade com características distintivas.

Mesmo que as escolas de maior prestígio se adaptem a novas regras eventualmente introduzidas como formas de barrar mecanismos segregadores e busquem novas brechas para a seleção, esta situação difere amplamente do contexto brasileiro. O não reconhecimento da disputa por escolas e das barreiras impostas seletivamente a alunos não permite a elaboração de regras que limitem/regulem tal seleção. Tal fato pode estar contribuindo, de forma mais acentuada do que nos quase mercados instituídos, para a geração de escolas mais homogêneas e para maior impacto da estratificação social dentro das redes escolares públicas.

\section{A REDE PÚBLICA DO RIO DE JANEIRO E O QUASE MERCADO OCULTO}

A rede pública da cidade do Rio de Janeiro é uma esfera interessante para se estudar o funcionamento dos mecanismos que chamamos de quase mercado oculto. Há forte distinção entre a zona sul e pequena parte da zona norte, que constituem as áreas mais abastadas da cidade, e a grande área da zona oeste e a maior parte da zona norte, espaços periféricos mais populares. Porém, uma característica marcante do modelo de segregação residencial da cidade do Rio de Janeiro é a proximidade física e a distância social entre segmentos. A presença de favelas ao longo da cidade e a concentração destas nas proximidades de partes mais abastadas são expressões claras desse modelo de segregação residencial. Mesmo que uma potencial composição heterogênea das escolas seja diminuída diante da estratificação público/ privado, ${ }^{9}$ a organização social do território permitiria maior mistura do alunado, já que diversos grupos sociais co-habitam regiões muito próximas. Entretanto, como estudos anteriores já indicaram, a concentração de diferentes segmentos sociais em um mesmo território não implica maior interação ou o estabelecimento de laços sociais que poderiam permitir a superação das distâncias sociais.

Além disso, não há no Rio de Janeiro restrições formais para a matrícula relacionada ao local de moradia dos alunos. Mesmo na ausência de políticas que claramente incentivem a escolha de estabelecimentos escolares, essa característica dos procedimentos de matrícula aumenta a possibilidade de escolha por parte dos pais.

Em outros trabalhos, mapeamos os passos da matrícula e do sistema público de ensino fundamental na cidade do Rio de Janeiro com base em entrevistas com membros da secretaria de educação e diretoras de escolas (Costa; Koslinski, no prelo).

9 A parte mais abastada da população geralmente usa os serviços educacionais das escolas privadas. 
Em primeiro lugar, destacamos que a maioria das escolas concentra seus alunos em um segmento do ensino fundamenta $1^{10}$ ou educação infantil. Mesmo as poucas escolas que ofertam os dois segmentos do ensino fundamental, geralmente, aumentam o número de vagas/turmas oferecidas no segundo segmento (ou a partir do $6^{\circ}$ ano do ensino fundamental). Ocorre, portanto, intensa movimentação de alunos entre escolas. Essa movimentação é parcialmente regulada nos polos de matrículas - subdivisões em grupos de oito, dez ou um pouco mais de escolas, com proximidade geográfica e oferta dos dois segmentos de ensino fundamental.

Havia até $2009,{ }^{11}$ basicamente, quatro fases na atribuição de matrículas aos alunos que estavam em fase de transição entre segmentos com mudança compulsória de escola. A primeira é o chamado remanejamento. No segundo semestre letivo, a direção solicitava aos pais e/ou responsáveis de alunos em vias de conclusão do primeiro segmento que preenchessem uma lista ordenada com três escolhas de estabelecimentos escolares para se fazer o remanejamento, desde que constassem do mesmo polo de matrícula. A partir dessas escolhas, as escolas se reuniam e as vagas das escolas receptoras eram distribuídas entre as que enviariam alunos.

A segunda etapa consistia na oferta pública das vagas remanescentes diretamente à demanda da população em geral, em datas predefinidas. Cada polo de matrícula, com todas as suas escolas, se reunia em um mesmo local e candidatos às vagas eram atendidos em sistema de matrícula informatizada on-line. Alunos provenientes de fora do sistema público municipal também poderiam ingressar.

Uma terceira etapa ocorria (e continua ocorrendo) diretamente nas escolas, passadas as fases anteriores, desde que essas ainda dispusessem de vagas. Nessa fase, a direção das escolas efetuava diretamente as matrículas dos alunos. Por fim, pode-se considerar a existência de uma quarta fase, de transferência, que se processa ao longo do ano escolar, também diretamente nas escolas.

Como se pode observar, não há exatamente um processo desregulado. Regras e procedimentos formais são estabelecidos. $\mathrm{O}$ resultado, entretanto, facilmente perceptível por meio de simples visita a escolas e reforçado pelas análises das trajetórias dos alunos, sugere ausência de aleatoriedade. As escolas tendem a certa homogeneidade socioeconômica. No caso do Rio de Janeiro, esse flagrante desfecho não pode ser ofuscado pela distribuição regional da desigualdade social, considerando as peculiaridades do modelo carioca de segregação residencial (Ribeiro; Alves; Franco, 2008). O fenômeno é tão mais visível conforme diferenças de cor estão associadas a diferenças socioeconômicas.

10 No Brasil, embora o ensino fundamental seja uma etapa única da educação básica, a história da sua organização e a normatização vigente estabelecida pelo Conselho Nacional e pelos Conselhos Estaduais de Educação o levou a uma divisão em dois segmentos. O primeiro segmento é composto por cinco séries e o segundo por quatro.

11 O sistema foi alterado de 2009 para 2010, com a introdução de uma possibilidade de escolha do estabelecimento escolar pelos pais por meio de um procedimento de matrícula informatizada, centralizada, por meio da qual pais e responsáveis preenchem uma lista ordinal de cinco opções preferenciais para alocação de seus dependentes. 
No entanto, na vertente qualitativa da pesquisa, pudemos identificar certas brechas em cada uma dessas etapas do processo de matrícula dos alunos que permitem discrição dos diretores e das burocracias escolares em relação à transferência e "seleção de alunos". Tais práticas dissimuladas incluem demanda dos pais induzida por diretores de escolas de primeiro segmento, círculos virtuosos e viciosos que se iniciam em instituições pré-escolares, bem como a transferência de alunos para escolas de reputação semelhante, seleção de alunos de acordo com um perfil específico e a suscetibilidade das burocracias escolares a influências patrimonialistas e clientelistas (Costa; Rosistolato; Prado, no prelo).

Este trabalho traz duas perspectivas diferentes daquelas que já realizamos anteriormente: (a) focaliza a transição entre o primeiro e o segundo segmento do ensino fundamental (ver seta preta na Figura 1); (b) focaliza uma área já consolidada da cidade (com pouco crescimento da população na última década), que abrange bairros contíguos, apresenta heterogeneidade socioeconômica e alta demanda por e oferta de escolas públicas de ensino fundamental.

O foco na transição do primeiro para o segundo segmento é interessante, uma vez que permite observar não somente o peso dos "convênios" entre escolas com reputação semelhante, como também, além da origem socioeconômica, o rendimento escolar dos alunos na alocação para diferentes escolas de segundo segmento.

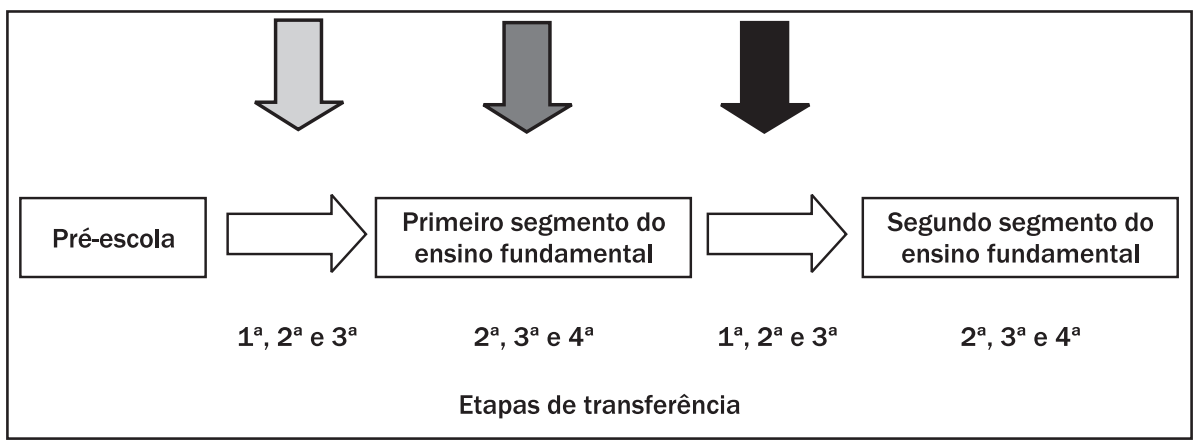

Figura 1 - Etapas de transferência e procedimentos de matrícula na rede pública municipal da cidade do Rio de Janeiro.

Fonte: Banco de dados da SME/RJ.

Elaboração dos autores.

O estudo de tais padrões pode nos oferecer algumas pistas sobre o efeito dos mecanismos relacionados ao funcionamento de um quase mercado oculto sobre a distribuição dos estudantes entre as escolas públicas de diferentes reputações.

A área selecionada para o estudo, na zona norte do Rio de Janeiro, chamou-nos a atenção não somente pela grande demanda e oferta de escolas públicas, como pela diferença entre as escolas no desempenho nas avaliações nacionais, e ainda pela diferença da composição do alunado em sua origem socioeconômica. 


\section{QUASE MERCADO OCULTO NO RIO DE JANEIRO: ALGUMAS EVIDÊNCIAS}

As análises apresentadas nesta seção tomam como base o banco de dados de alunos da SME da cidade do Rio de Janeiro, que contém informações sobre a escolarização dos pais, raça, gênero, desempenho escolar dos estudantes e suas transferências entre escolas e entre turmas no período de 2004 a 2009. As análises também contaram com dados de escolas com informações geocodificadas e de desempenho em testes nacionais padronizados, a saber, Prova Brasil, 2005, 2007, 2009.

$\mathrm{O}$ estudo se restringe à transição de alunos entre segmentos do ensino fundamental (do $5^{\circ}$ ano para o $6^{\circ}$ ano), de 2008 para 2009, considerando escolas de segundo segmento localizadas em uma área da cidade que apresenta as seguintes características: (a) alta demanda por e oferta de escolas de ensino fundamental; (b) alta diversificação de escolas no desempenho e na composição do alunado; (c) área caracterizada por territórios contíguos com Índice de Desenvolvimento Social (IDS) diferenciado.

Uma exploração inicial no banco de dados da SME permitiu a seleção de dois bairros vizinhos situados na zona norte da cidade, Cordovil e Irajá. As escolas, com seus respectivos alunos, em foco no estudo foram selecionadas em um raio de dois quilômetros, com centro em duas escolas ${ }^{12}$ localizadas nessa área da cidade e que apresentaram os maiores resultados médios regionais nas avaliações nacionais de 2005,2007 e 2009. Consideramos na análise todas as escolas públicas que oferecem o segundo segmento do ensino fundamental contidas nesse raio de distância. Também consideramos que o público que mora nessa extensão estaria em disputa por essas escolas, mesmo sabendo que parte dos alunos que frequentam as escolas de alto prestígio vem de outros bairros e percorre grande distância para ter acesso a esse bem escasso.

Dessa forma, a amostra contém alunos que em 2009 estavam matriculados no $6^{\circ}$ ano das 21 escolas contidas na área abrangida pela pesquisa. Com a característica longitudinal do banco, foi possível determinar em que escolas os alunos estavam matriculados em 2008 e mapear certas características ou padrões da transição entre o primeiro e o segundo segmento do ensino fundamental. Dessa amostra foram excluídos os alunos que ficaram retidos no $5^{\circ}$ ano do ensino fundamental de 2008 para 2009, tendo em vista que esses alunos não participaram do processo de transição, foco desta análise.

A Figura 2 mostra a distribuição das escolas de segundo segmento dentro das circunferências traçadas pelo raio de distância estabelecido a partir dos critérios aqui já descritos. Com base no mapa, é possível identificar a proximidade física aliada à diversidade de desempenho dos estabelecimentos escolares, calculados a partir da média de cada escola na Prova Brasil de 2005, 2007 e 2009. ${ }^{13}$

12 As duas escolas centrais são próximas e, portanto, estavam contidas em um raio de dois quilômetros uma da outra.

13 A Prova Brasil foi criada em 2005 a fim de complementar o Sistema Nacional de Avaliação da Educação Básica (SAEB). A prova avalia estudantes que frequentam o $5^{\circ}$ 


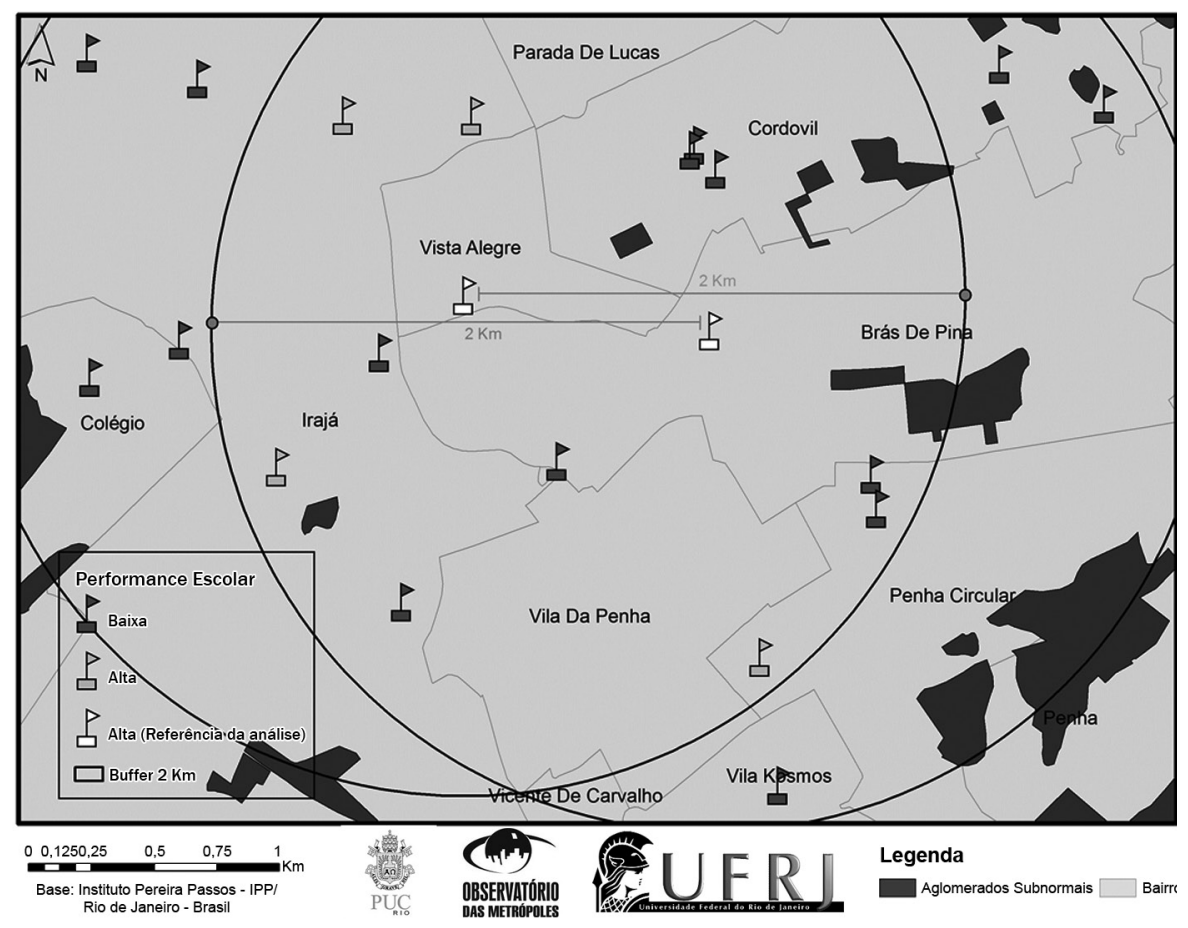

Figura $2^{14}$ - Distribuição das escolas selecionadas pelo território e o seu desempenho médio na Prova Brasil de 2005, 2007 e $2009 .{ }^{15}$

Fonte: Banco de dados da SME/RJ.

Elaboração de Caio Victer.

A seguir, a Figura 3 expressa forte coincidência entre a posição relativa das escolas, quanto ao desempenho médio em avaliação externa (Figura 2), e o nível de escolarização dos pais dos estudantes, conforme era previsível. Infelizmente, para este artigo ainda não podemos proceder a análises que destaquem aspectos territoriais, mas o olhar inicial sobre os mapas sugere que a distância entre as escolas e as áreas de favelas pode agregar capacidade explicativa aos processos de distribuição de oportunidades escolares, conforme apresentado em Costa et al. (2010).

e o $9^{\circ}$ ano do ensino fundamental nas áreas de língua portuguesa e matemática. Essa avaliação é quase universal, pois é aplicada em escolas públicas localizadas nas zonas urbanas que possuem mais de 20 alunos na série avaliada. Disponível em: <http://provabrasil.inep.gov.br>. Acesso em: 10 abr. 2010.

14 Agradecemos a contribuição de Caio Victer pela gentil elaboração dos mapas apresentados nas Figuras 2 e 3 deste artigo.

15 Os nomes apresentados no mapa correspondem a bairros da cidade. 


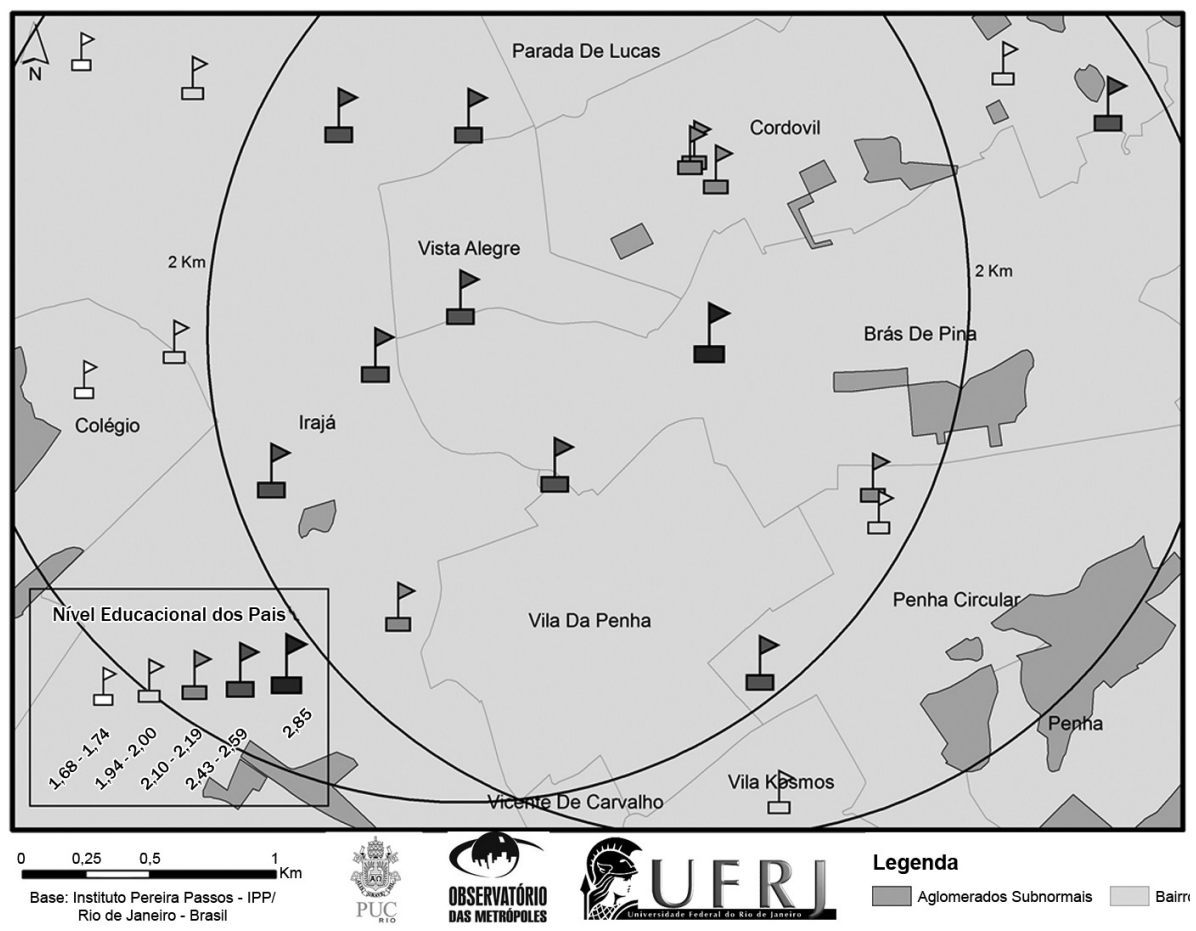

Figura 3 - Distribuição das escolas de segundo segmento (2009) de acordo com a máxima escolaridade dos pais. Fonte: Banco de dados da SME/RJ.

Elaboração de Caio Victer.

As análises a seguir mostram as tendências dos fluxos entre escolas de primeiro e segundo segmentos, bem como as probabilidades de acesso a escolas de desempenho diferenciado. O Quadro 1 descreve as variáveis utilizadas nas análises. 
Quadro 1 - Variáveis utilizadas na investigação

\begin{tabular}{|c|c|c|}
\hline Variáveis & Tipo & Descrição \\
\hline \multicolumn{3}{|l|}{ Variáveis dependentes } \\
\hline $\begin{array}{l}\text { Desempenho da escola de } \\
\text { primeiro segmento de ensino } \\
\text { fundamental em } 2008\end{array}$ & Dummy ${ }^{16}$ & $\begin{array}{l}\text { Indica se o aluno estava matriculado em uma } \\
\text { escola municipal com bom desempenho (quartil } \\
\text { superior na Prova Brasil) no } 5^{\circ} \text { ano do ensino } \\
\text { fundamental em } 2008 \text { ( } 1=\operatorname{sim} / 0=\text { não) } \\
\end{array}$ \\
\hline $\begin{array}{l}\text { Desempenho da escola de } \\
\text { segundo segmento de ensino } \\
\text { fundamental em } 2009\end{array}$ & Dummy & $\begin{array}{l}\text { Indica se o aluno estava matriculado em uma escola } \\
\text { municipal na cidade do Rio de Janeiro com bom } \\
\text { desempenho (quartil superior na Prova Brasil) no } 6^{\circ} \\
\text { ano do ensino fundamental em } 2009 \text { ( } 1=\operatorname{sim} / 0=\text { não) } \\
\end{array}$ \\
\hline \multicolumn{3}{|l|}{ Variáveis explicativas } \\
\hline $\begin{array}{l}\text { Desempenho da escola de } \\
\text { primeiro segmento de ensino } \\
\text { fundamental em } 2008\end{array}$ & Dummy & $\begin{array}{l}\text { Indica se o aluno estava matriculado em uma } \\
\text { escola municipal com bom desempenho (quartil } \\
\text { superior na Prova Brasil) no } 5^{\circ} \text { ano do ensino } \\
\text { fundamental em } 2008 \text { ( } 1=\operatorname{sim} / 0=\text { não) } \\
\end{array}$ \\
\hline Máxima educação dos pais & Ordinal & $\begin{array}{l}\text { Indica o nível máximo de escolaridade dos pais } \\
\text { do aluno }(0=\text { analfabeto/ } 1=\text { ensino fundamental } \\
\text { incompleto/ } 2=\text { ensino fundamental } / 3= \\
\text { ensino médio/ } 4 \text { = educação superior })\end{array}$ \\
\hline Distorção idade-série & Dummy & $\begin{array}{l}\text { Indica se aluno apresenta idade superior à } \\
\text { prevista para a série }(1=\operatorname{sim} / 0=\text { não })\end{array}$ \\
\hline $\begin{array}{l}\text { Organização familiar } \\
\text { biparental }\end{array}$ & Dummy & Indica se o aluno mora com a mãe e o pai $(1=\operatorname{sim} / 0=$ não $)$ \\
\hline Sexo masculino & Dummy & Indica se aluno é do sexo masculino (1=sim/0=não) \\
\hline Cor branca & Dummy & Indica se o aluno é branco ( $1=\operatorname{sim} / 0=$ não $)$ \\
\hline
\end{tabular}

Fonte: Banco de dados da SME/RJ.

Elaboração dos autores.

O Quadro 2 apresenta a quantidade e a porcentagem de alunos que estavam em 2008 em escolas de primeiro segmento com baixo desempenho e outros em escola de alto desempenho, e que conseguiram vagas em escolas com o mesmo nível correspondente de desempenho no segundo segmento em 2009.

16 A variável Dummy nada mais é que uma variável binária. 
Quadro 2 - Transição do $5^{\circ}$ ano para o $6^{\circ}$ ano de acordo com o desempenho da escola de origem em 2008

\begin{tabular}{|c|c|c|c|c|c|}
\hline & & & \multicolumn{2}{|c|}{$\begin{array}{c}\text { Desempenho da escola } \\
\left(6^{0} \text { ano }-2009\right)\end{array}$} & \multirow[b]{2}{*}{ Total \% } \\
\hline & & & Baixo & Alto & \\
\hline \multirow{3}{*}{$\begin{array}{l}\text { Desempenho da escola } \\
\quad\left(5^{\circ} \text { ano }-2008\right)\end{array}$} & Baixo & Total & 1.460 & 202 & 1.662 \\
\hline & & $\%$ & 87,8 & 12,2 & 100 \\
\hline & Alto & Total & 280 & 277 & 557 \\
\hline & & $\%$ & 50,3 & 49,7 & 100 \\
\hline & Total & Total & 1.740 & 479 & 2.219 \\
\hline & & $\%$ & 78,4 & 21,6 & 100 \\
\hline
\end{tabular}

Nota: Pearson Chi-Square $=85,758 \mathrm{p}<0,000$.

Fonte: Banco de dados da SME/RJ (2008 e 2009).

Elaboração dos autores.

O Quadro 2 sugere que há clara tendência a que estudantes em escolas de baixo desempenho médio mantenham suas matrículas em escolas do mesmo padrão, na passagem entre os dois segmentos do ensino fundamental estudados. Parece ocorrer também forte mobilidade decendente entre os estudantes originariamente de escolas de desempenho mais alto, no primeiro segmento, quando remanejados para a fase consecutiva. Surpreendendo nossas expectativas iniciais, a permanência dos estudantes em escolas de topo, na distribuição observada, ficou em torno de apenas metade dos estudantes. Ainda que proporcionalmente poucos $(12,2 \%$ em relação ao universo dos alunos em escolas de baixo desempenho em 2008), os estudantes com "mobilidade escolar ascendente" são mais de $40 \%$ que vão compor o alunado das escolas de melhor desempenho médio, no $6^{\circ}$ ano, em 2009.

O resultado encontrado demanda estudos específicos que procurem compreender o fenômeno do ponto de vista social e pedagógico. Considerando a cultura pedagógica e as políticas educacionais adotadas ao longo das duas ou três últimas décadas, a avaliação mais rigorosa dos estudantes e o uso de procedimentos como a reprovação foram se deslocando para além das séries iniciais da escola obrigatória. É possível que mecanismos seletivos mais severos, que dão sequência àqueles operados no acesso inicial ao sistema, operem destacadamente nessa transição entre segmentos, quando ocorre certa reorganização na rede escolar.

Vale registrar que o Quadro 2 sugere a existência de um padrão na passagem entre os segmentos, com maior probabilidade de que um estudante proveniente de escola de bom desempenho permaneça nesse tipo de escola, do que um outro, oriundo de uma escola de baixo desempenho médio, tenha acesso a ela. 


\section{Gráfico 1 - Distribuição percentual dos alunos nas escolas em 2009 de acordo com a máxima escolaridade dos pais}

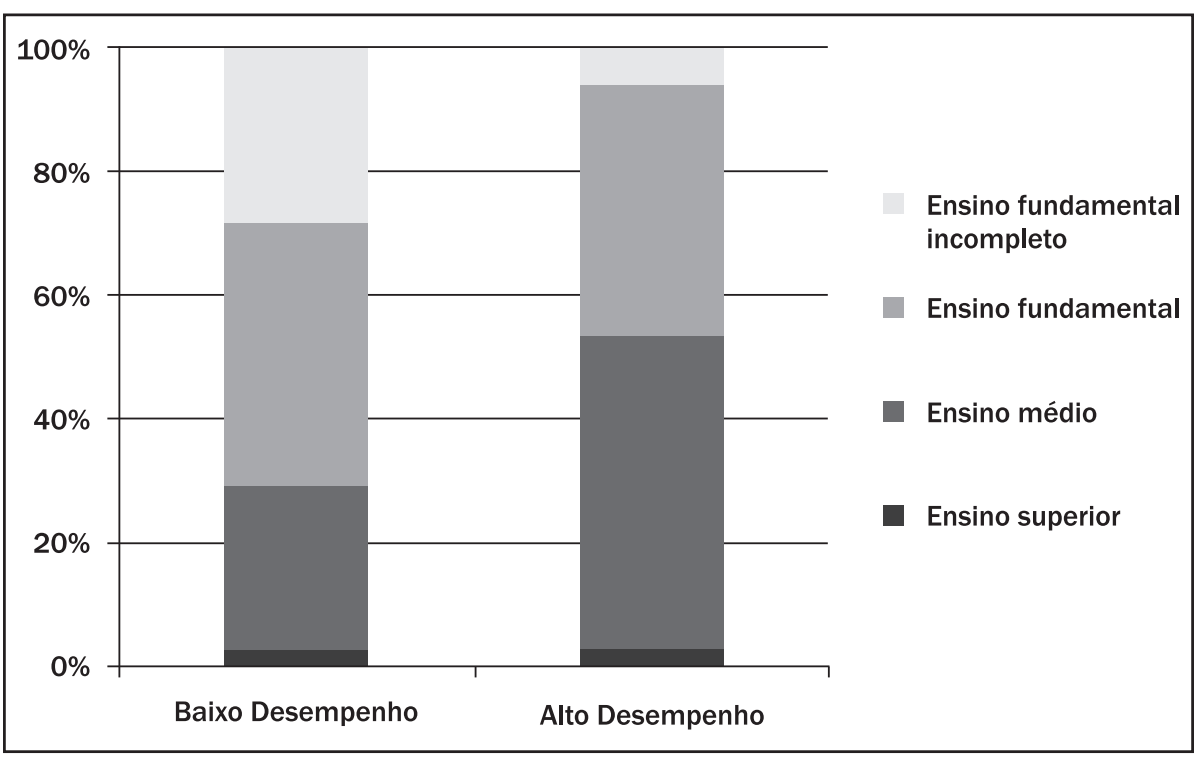

Fonte: Banco de dados da SME/RJ (2009).

Elaboração dos autores.

O Gráfico 1 apresenta marcantes diferenças, conforme é clássico na sociologia da educação, associando a escolaridade dos pais, indicativa do capital cultural familiar, e o tipo de grupamento escolar em que os filhos estão inseridos. Por se tratar de uma região relativamente pobre da cidade, o nível de escolaridade dos pais em geral é baixo.

O desequilíbrio entre a escolaridade dos pais nos dois grupos, cujos filhos estavam em escolas pertencentes a grupo distintos, se revela sobretudo na grande distância percentual dos subgrupos que não concluíram o ensino fundamental e que concluíram o ensino médio. Enquanto apenas $6 \%$ dos pais dos alunos matriculados em escolas de alto desempenho não concluíram o ensino fundamental, nas escolas de baixo desempenho o percentual atinge $28,5 \%$. Invertendo a situação, a taxa de conclusão do ensino médio chega a 46,2\% nas escolas de alto desempenho e fica em $26,5 \%$ no outro grupo. Comparando os dados, percebemos que $53,2 \%$ dos pais dos alunos matriculados em escolas com alto desempenho possuíam ensino médio ou educação superior, enquanto $70,9 \%$ dos pais dos alunos matriculados em escolas com baixo desempenho possuíam no máximo o ensino fundamental completo. 
Gráfico 2 - Comparação entre percentual de alunos em situação de distorção idade-série em 2009 em escolas de baixo e alto desempenho

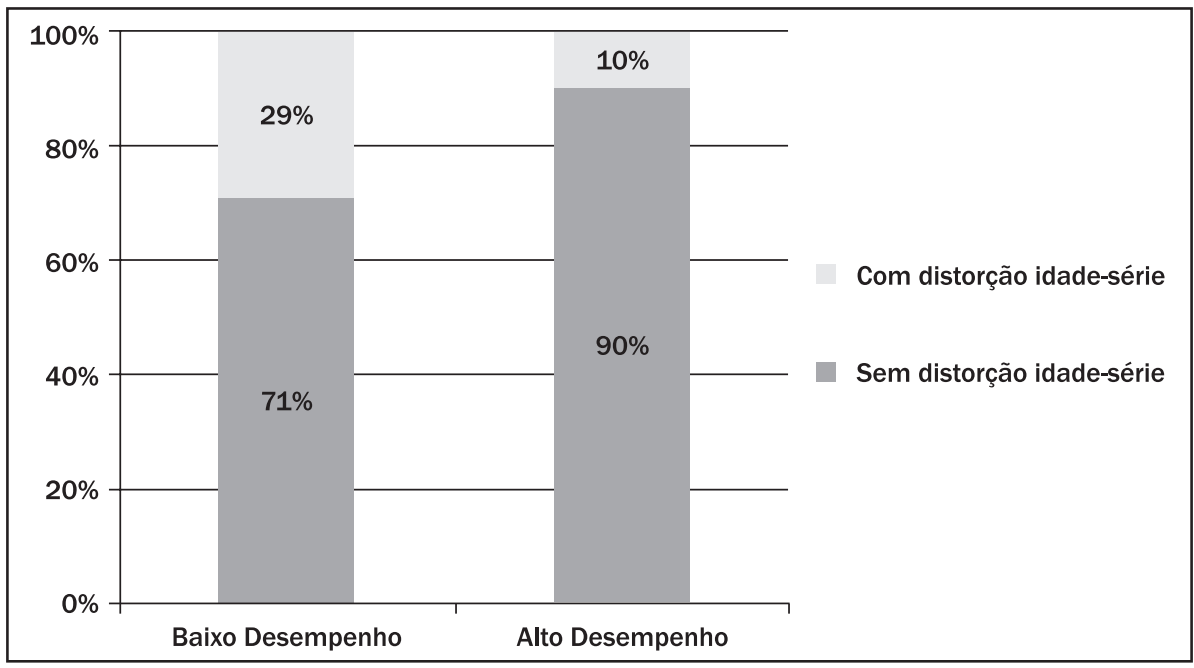

Fonte: Banco de dados da SME/RJ (2009).

Elaboração dos autores

Concluindo o panorama descritivo, apresentamos a clara diferenciação entre escolas de baixo e alto desempenho médio, no que diz respeito à distorção idade-série dos alunos. Como era previsível, as escolas de menor desempenho relativo são compostas por contingente bem mais elevado de alunos com algum atraso em sua trajetória escolar. As diferenças entre os grupos de alunos são acentuadas, pois apenas $10 \%$ dos alunos matriculados no $6^{\circ}$ ano do ensino fundamental nas escolas de alto desempenho em 2009 estavam com idade maior do que a esperada para a série, em contraposição a $29 \%$ em escolas de baixo desempenho. De alguma forma, a própria existência desse atraso já é indicativa de desempenho escolar mais baixo, medido por meio de testes padronizados.

É importante explicar que a informação sobre distorção idade-série pode estar subestimada, pois todos os alunos nascidos entre 1997 e 2000, portanto com idade entre 9 e 12 anos, foram considerados na idade esperada para o $6^{\circ}$ ano em 2009; e todos os alunos nascidos entre 1991 e 1996 foram considerados em situação de distorção idade-série, independente do número de anos em atraso. A opção por construir a variável dessa forma deveu-se à consideração da possibilidade de matrícula inicial com até 7 anos completos na $1^{\text {a }}$ série do ensino fundamental com oito anos de duração, ${ }^{17}$ pois, caso contrário, estaríamos

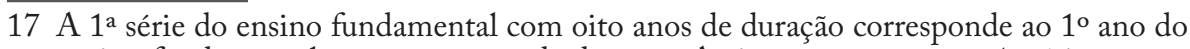
ensino fundamental com nove anos de duração. Assim, por extensão, a $4^{\mathrm{a}}$ série corresponde ao $5^{\circ}$ ano e a $5^{\mathrm{a}}$ série corresponde ao $6^{\circ}$ ano. 
certamente superestimando a situação de atraso, o que poderia potencializar o poder explicativo dessa variável.

Dando início ao processo analítico multivariado, estimamos as chances de os estudantes da amostra estarem em uma escola de alto ou baixo desempenho relativo no final do $5^{\circ}$ ano de escolaridade, em 2008, antes, portanto, de passarem pela transição entre o primeiro e o segundo segmento do ensino fundamental. Essa regressão é apresentada com a finalidade de permitir melhor compreensão dos esquemas de construção da desigualdade de oportunidades escolares. Nosso objeto é a transição entre dois segmentos de ensino, mas a distribuição anterior a essa fase já se encontra marcada por mecanismos seletivos e hierarquizadores que implicam uma composição escolar tendente à homogeneidade, desde o processo inicial de escolarização.

Quadro 3 - Regressão logística estimando as chances de o estudante estar em escolas de alto desempenho no final do primeiro segmento do ensino fundamental em 2008

\begin{tabular}{|l|c|}
\hline & $\operatorname{Exp}(\mathrm{B})$ \\
\hline Máxima escolaridade dos pais & $2.26^{* * *}$ \\
\hline Atraso idade-série & $0.63^{* *}$ \\
\hline Família biparental & $1.28^{*}$ \\
\hline Sexo masculino & 0.90 \\
\hline Cor branca & 1.19 \\
\hline Constante & 0.05 \\
\hline
\end{tabular}

**** $p \leq 0.001 * \mathrm{*} p \leq 0.01 * \mathrm{p} \leq 0.05$.

Fonte: Banco de dados da SME/RJ (2008 e 2009).

Elaboração dos autores.

O Quadro 3 mostra maiores chances de alunos com pais mais escolarizados e de família biparental estarem em escolas de alto desempenho no final do primeiro segmento. Alunos brancos possuem maiores chances de estarem nessa situação; entretanto, os resultados não são estatisticamente significativos. Já alunos com atraso escolar apresentam menores chances de estarem em escolas de alto desempenho.

O Quadro 4 apresenta a sequência de modelos criados para estimar as probabilidades de alunos chegarem a uma escola no quartil superior do desempenho, na área estudada, no $6^{\circ}$ ano escolar, em 2009. São dois modelos independentes. Em ambos, o primeiro passo é estimar a razão de chance do acesso à escola de alto desempenho relativo (em 2009), considerando apenas a escola anterior do aluno (2008). Em seguida, foram acrescidas variáveis explicativas, no nível dos alunos e de sua família. 
Quadro 4 - Regressão logística estimando o acesso à escola de melhor desempenho no $6^{\circ}$ ano do ensino fundamental em 2009

\begin{tabular}{|l|c|c|c|c|}
\hline \multirow{2}{*}{} & \multicolumn{2}{|c|}{ Modelo A } & \multicolumn{2}{c|}{ Modelo B } \\
\cline { 2 - 5 } & Step 1 & Step 2 & Step 1 & Step 2 \\
\cline { 2 - 5 } & $\operatorname{Exp}(\mathrm{B})$ & $\operatorname{Exp}(\mathrm{B})$ & $\operatorname{Exp}(\mathrm{B})$ & $\operatorname{Exp}(\mathrm{B})$ \\
\hline $\begin{array}{l}\text { Desempenho médio da escola } \\
\text { em 2008 (dicotômica) }\end{array}$ & $7,15^{* * * * *}$ & $5.55^{* * * * *}$ & $3.25^{* * * *}$ & $2.70^{* * * * *}$ \\
\hline Máxima escolaridade dos pais & - & $1.64^{* * * *}$ & - & $1.76^{* * * * *}$ \\
\hline $\begin{array}{l}\text { Atraso idade-série } \\
\text { (dicotômica) }\end{array}$ & - & $0.58^{* * *}$ & - & $0.47^{* * * *}$ \\
\hline Família biparental & - & $1.27^{+}$ & - & $1.39^{*}$ \\
\hline Sexo masculino & - & 1.07 & - & 1.06 \\
\hline Cor branca & - & 0.96 & - & 0.89 \\
\hline Constante & 0,138 & 0.42 & 0.16 & 0.04 \\
\hline Número de casos & 2.219 & 1.814 & 1.636 & 1.369 \\
\hline
\end{tabular}

*** $p \leq 0.001{ }^{* *} \mathrm{p} \leq 0.01 * \mathrm{p} \leq 0.05^{+} \mathrm{p} \leq 0.10$.

Fonte: Banco de dados da SME/RJ (2008 e 2009).

Elaboração dos autores.

Os modelos A e B diferem apenas em um aspecto. No modelo A, estão presentes todos os alunos da amostra. No modelo B, foram removidos os alunos que permaneceram em suas escolas na transição entre essas séries escolares, considerando que algumas escolas ofereciam todos os nove anos da escolaridade fundamental. Geramos esse segundo modelo pensando em clarear a compreensão do fenômeno de possíveis efeitos inerciais de permanência nas escolas, buscando acentuar os possíveis processos seletivos na transferência entre escolas. Como se pode observar, o número de casos reduzido não prejudicou a capacidade explicativa das variáveis, auxiliando no exercício de identificar os pesos relativos de cada um dos aspectos aqui tratados.

Os Gráficos 3 e 4 apresentam os valores dos coeficientes destacados no Quadro 4. As barras identificam o aumento ou a diminuição da chance de acesso às escolas de alto desempenho. Estudar em uma escola de alto prestígio no final do primeiro segmento é a variável de maior poder explicativo nos dois modelos, e seu impacto na chance de obter vaga em uma escola de alto desempenho no segundo segmento está controlado pelas demais variáveis do modelo. Dessa forma, o Gráfico 4 indica que um aluno que estudou no primeiro segmento em uma escola de alto desempenho tem $170 \%$ mais de chance de ingressar em uma escola de alto desempenho no $6^{\circ}$ ano, se comparado aos seus pares com as mesmas características, mas que estudaram em uma escola de baixo desempenho no primeiro segmento. 
Gráfico 3 - Regressão logística estimando o acesso à escola de melhor desempenho no $6^{\circ}$ ano do ensino fundamental - "com efeito inércia"

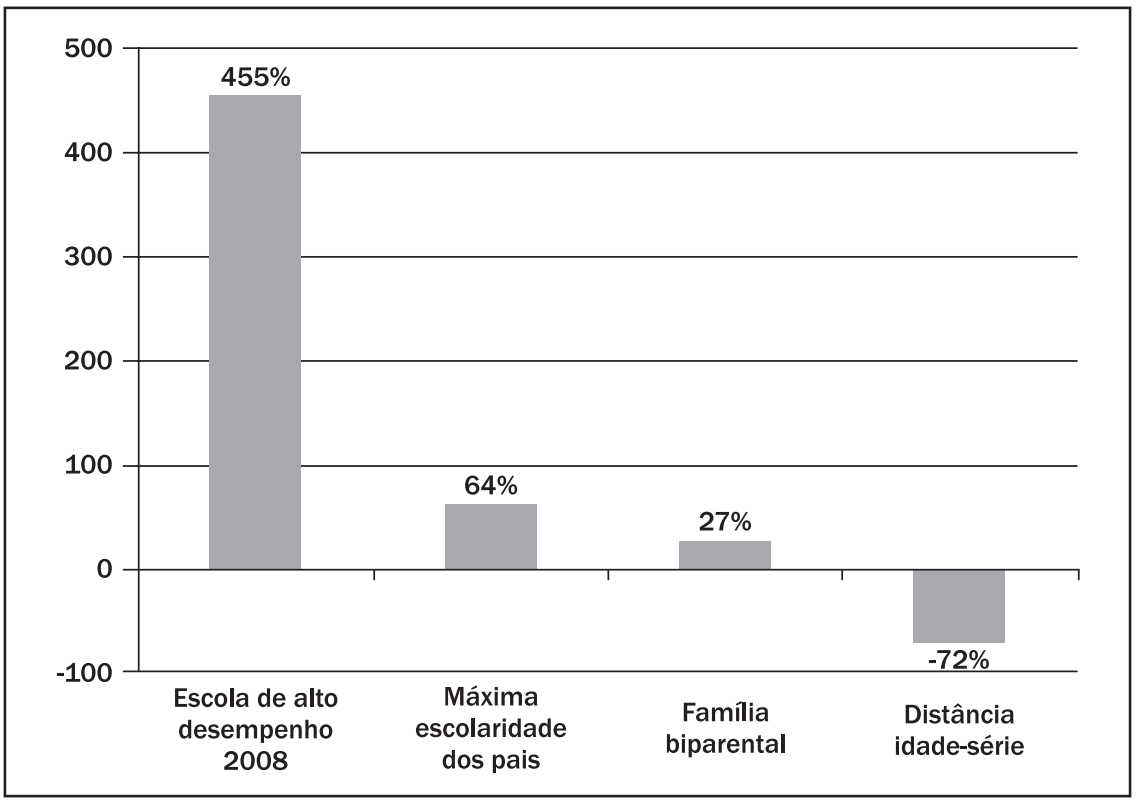

Fonte: Banco de dados da SME/RJ.

Elaboração do autor.

Gráfico 4 - Regressão logística estimando o acesso à escola de melhor desempenho no $6^{\circ}$ ano do ensino fundamental - "sem efeito inércia"

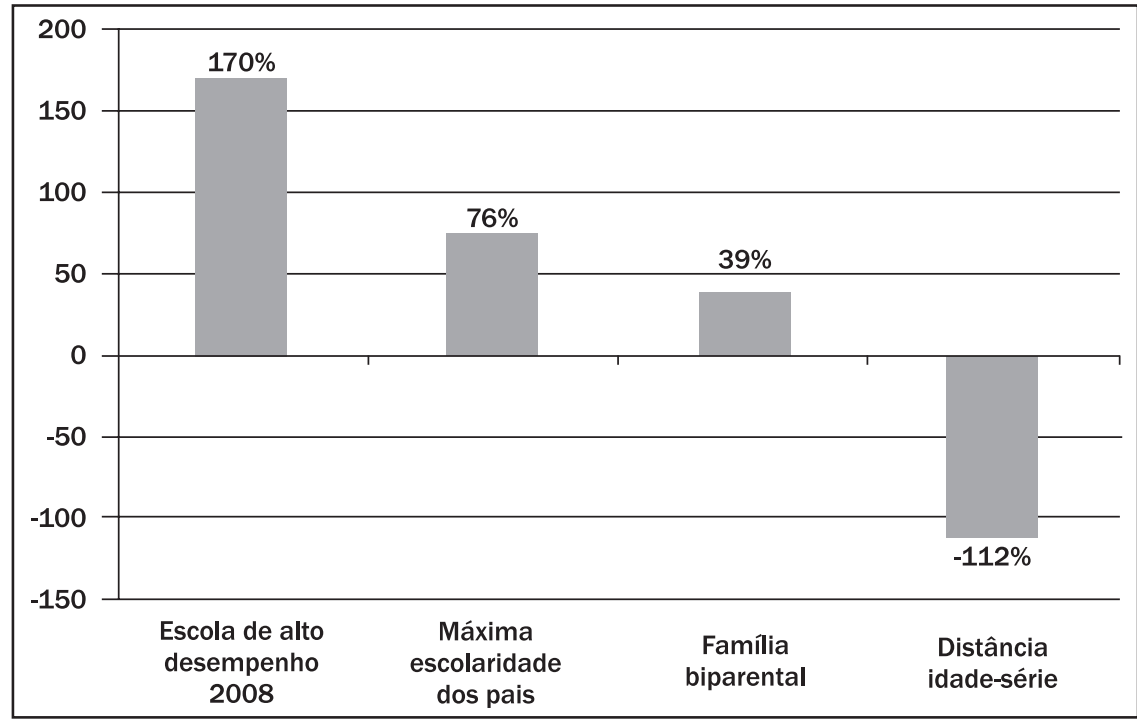

Fonte: Banco de dados da SME/RJ.

Elaboração dos autores. 
Os dados expõem a existência de mecanismos seletivos no processo de transição entre o primeiro e o segundo segmento do ensino fundamental, na cidade do Rio de Janeiro, em sua rede escolar pública municipal. Ao escolhermos uma área circunscrita da cidade, com alta concentração populacional e ampla rede de possíveis escolhas escolares, procurávamos destacar o fenômeno da ecologia do quase mercado escolar, que, conforme a literatura apresentada, condiciona as trajetórias escolares dos estudantes modelando como que trackings, sem que haja políticas deliberadas para fazê-lo. A definição tende a ser muito precoce e apenas parcialmente condicionada pela própria trajetória escolar dos estudantes.

Nossa base de dados, no ponto em que se encontra disponível para uso confiável, ${ }^{18}$ não nos permite ainda ter indicadores mais específicos de desempenho dos estudantes. Por essa razão, adotamos apenas um indicador do atraso na idade com relação à série em que cada aluno deveria estar, como sugestivo do desempenho/ trajetória escolar dos estudantes.

Lamentavelmente, não pudemos dispor de dados mais efetivos do nível socioeconômico dos alunos. Nas bases de dados utilizadas, não existem informações que nos permitam compor uma imagem mais precisa desse indicador. Para o futuro, com o georreferenciamento previsto da residência dos estudantes, será possível estimar tal índice, com base no local de moradia. Por ora, apenas a informação acerca da escolaridade dos pais/responsáveis pelos alunos estava disponível, o que pode ser considerado uma proxy (fraca) do nível socioeconômico, mas é bom indicador do capital cultural, elemento-chave em toda a literatura, para instruir, orientar e promover acesso a escolhas de estabelecimentos escolares mais "qualificados".

Destacamos essas variáveis, pois foram as que funcionaram (ou porque são conceitualmente relevantes, apesar de não significativas na análise da pequena porção da base que utilizamos) no modelo logístico desenvolvido para estimar as chances de acesso a uma escola considerada de melhor desempenho médio relativo, no $6^{\circ}$ ano, em 2009. Como esperado, a origem em uma escola de mesmo padrão é o principal fator preditivo do fenômeno, mas o atraso escolar e o peso do capital cultural também estão presentes de forma significativa e crescem, conforme focalizamos apenas os alunos que trocam de escola na transição estudada. Resta ainda algum destaque para um componente pouco explorado na sociologia da educação brasileira, referente à composição familiar dos alunos. Ainda que não muito claros em seus mecanismos operacionais, nossos estudos têm apresentado efeitos interessantes de indicadores da estrutura familiar dos alunos (Costa, 2010). No presente estudo, é possível que a variável dicotômica "família biparental" esteja confundida

18 Desde março de 2011, com acesso a diversas bases de dados atualizadas da SME/RJ, temos tido a oportunidade de explorar mais detidamente as questões aqui enfocadas. Não é possível, porém, ainda, por características constitutivas de tais bases, trabalharmos com várias das informações que aqui gostaríamos de explorar, uma vez que não foram construídas com finalidades de pesquisa. Temos trabalhado para tornar os dados das diversas bases plenamente utilizáveis em nossas análises. 
com o nível socioeconômico dessas famílias, dado que famílias biparentais tendem a ter melhores condições socioeconômicas.

No futuro breve, nossos estudos qualitativos, a exploração mais rica e complexa das bases de dados, o georreferenciamento da residência dos estudantes, e, sobretudo, a realização de um grande survey domiciliar permitirão que sejam investigados com maior abrangência e com mais recursos analíticos os mecanismos de distribuição de oportunidades escolares que, conjugados à dimensão da escolha familiar, ajudam a compreender a forte desigualdade educacional brasileira.

\section{CONCLUSÃO}

O debate relacionado à democratização do acesso, permanência e qualidade do ensino permanece não apenas atual como necessário à reflexão sobre a garantia do direito à educação e a distribuição de oportunidades escolares. Diante da complexidade dos sistemas educacionais e das limitações metodológicas dessa pesquisa, não foi intenção do estudo construir generalizações sobre todo o sistema público de ensino da cidade do Rio de Janeiro. Entretanto, acreditamos que as análises aqui apresentadas podem ajudar a identificar possíveis critérios ocultos de seleção de alunos, que podem ter impacto no aumento das desigualdades de oportunidades educacionais.

As reflexões que apresentamos neste artigo foram suscitadas, inicialmente, pela percepção das diferenças entre instituições escolares comuns, que compõem a mesma rede de ensino, tanto do ponto de vista dos resultados das avaliações nacionais quanto da composição de seu alunado, ou seja, das características da população que atende. Tais diferenças, descritas ao longo do artigo, sugerem uma seleção de alunos no acesso às escolas de alto desempenho relativo. Tal dinâmica pode ser analisada com base em categorias descritas pelas teorias de quase mercado escolar.

A análise descritiva do processo de transição entre o primeiro e o segundo segmento do ensino fundamental indicou a existência de padrões de transferência não aleatórios dos alunos entre as instituições escolares. A escola que o aluno frequentou no $5^{\circ}$ ano do ensino fundamental determina em grande medida suas chances relativas de conseguir uma vaga em uma escola de alto desempenho na continuidade dos estudos. As chances de mobilidade ascendente no modelo são pequenas e podem diminuir ou aumentar dependendo da trajetória escolar do aluno e das características de sua família.

Cabe ressaltar que a variável mais importante para a estimação das chances de acesso a escolas de alto desempenho no segundo segmento do ensino fundamental foi a escola de origem do aluno - Desempenho da escola 2008. Os dados sugerem a tendência a uma definição precoce das trajetórias escolares que serão trilhadas ao longo do ensino fundamental, pois o acesso inicial na rede pública a escolas de alto desempenho está condicionado parcialmente pelas características socioeconômicas das famílias (Costa et al., 2010). 
Outras pesquisas realizadas sobre o tema, algumas citadas ao longo do texto, indicam a importância de outras variáveis que não analisamos nesta fase do estudo, como, por exemplo, a questão territorial, o rendimento escolar do aluno e a moradia da família. Verifica-se a necessidade de continuidade e aprofundamento deste estudo, com dados representativos de toda a rede municipal, com o objetivo de contribuir para a compreensão do fenômeno de seleção de alunos em escolas públicas comuns. Os dados apresentados significam um alerta sobre como as escolas podem contribuir para reproduzir quadros de desigualdade social. Especialmente, a incorporação de dados sobre o desempenho dos alunos, medidos por meio de avaliações internas e externas às escolas, proporcionará um salto importante em nossos modelos analíticos, o que deverá ocorrer em breve. Se controlados os efeitos das diferenças de desempenho, persistirem os condicionantes adscritos impactando fortemente as chances de acesso a escolas hierarquizadas, o alerta ganha reforço.

\section{REFERÊNCIAS}

Alves, Maria Tereza Gonzaga; Soares, José Francisco. Efeito-escola e estratificação escolar: o impacto da composição das turmas por nível de habilidades dos alunos. Educação em Revista, Belo Horizonte, UFMG, n. 45, p. 25-59, jun. 2007.

Berends, Mark; Zottola, Genevieve C. Social perspectives on school choice. In: Berends, Mark et al. Hand book of research on school choice. New York: Routledge, 2009.

Brooke, Nigel; Soares, José Francisco. Pesquisa em eficácia escolar: origem e trajetórias. Belo Horizonte: Editora UFMG, 2008.

Coleman, James. Some points on choice in education. Sociology of Education, Sernau, Scott, v. 65, n. 4, p. 260-262, out. 1992.

Costa, Marcio. Famílias e acesso diferenciado a escolas públicas prestigiadas: um estudo de caso. Educação em Revista, Belo Horizonte, UFMG, v. 26, n. 2, p. 227-248, 2010.

.Prestígio e hierarquia escolar: estudo de caso sobre diferenças entre escolas em uma rede municipal. Revista Brasileira de Educação, Rio de Janeiro, ANPEd; Campinas, Autores Associados, v. 13, n. 39, p. 455-469, 2008.

; Koslins KI, Mariane Campelo. Escolha, estratégia e competição por escolas públicas. Pro-Posições, Campinas, UNICAMP (no prelo).

Costa, Marcio et al. Quase mercado escolar em contexto de proximidade espacial e distância social: o caso do Rio de Janeiro. In: Colóquio Luso-Brasileiro de Sociologia da Educação, 2., 2010, Portalegre. Anais... Portalegre/Portugal, 2010.

; Rosistolato, Rodrigo; Prado, Ana. "Talvez se eu tivesse algum conhecimento...”: caminhos possíveis em um sistema educacional público e estratificado. Interseções, Rio de Janeiro, UERJ, (no prelo).

Glenn, Charles. School segregation and virtuous markets. In: Penser Les Marches Scolaires. Genebra/Suíça: mar. 2009. Disponível em: <http://www.unige.ch/fapse/ ggape/seminaire/programme/progvendredi13/Glenn.pdf>. Acesso em: 11 fev. 2011. 
Gorard, Stephen; Taylor, Chris; Fitz, John. Schools. Markets and choice policies. New York: Routledge Falmer, 2003.

Holme, Jennifer Jellison. Buying homes, buying schools: school choice and the social construction of school quality. Harvard Educational Review, Harvard Education Publishing Group, Cambridge, v. 72, n. 2, p. 177-205, jun./ago. 2002.

Le Grand, Julian. Quasi-markets and social policy. The Economic Journal, v. 101, p. 1.256-1.267, set. 1991.

Medeiros, Camila de Sousa Lanes. Quase mercado escolar: uma pesquisa domiciliar em Angra dos Reis. 2011. Dissertação (Mestrado em Educação) - Universidade Federal do Rio de Janeiro, Rio de Janeiro, 2011.

Poupeau, Franck; Françors, Jean-Chistophe. Le sens du placement. Ségrégation résidentielle et segregation scolaire. Paris: Raisons d'Agir Éditions, jan. 2008.

Ribeiro, Luiz Cesar de Queiroz; Alves, Fátima; Franco, Creso. Segregación urbana y rezago escolar en Río de Janeiro. Revista de la CEPAL, CEPAL, Santiago de Chile, n. 94, p. 133-148, abr. 2008.

Rist, Ray C. On understanding the processes of schooling: the contributions of labeling theory. In: Karabel, Jerome; Halsey, Albert Henry (Orgs.). Power and ideology in education. New York: Oxford University Press, 1977.

Thrupp, Martin. School admissions and the segregation of school intakes in New Zealand Cities. Urban Studies, Sage Publications, Reino Unido, v. 44, n. 7, p. 1.393-1.404 , jun. 2007.

Veloso, Fernando et al. Educação básica no Brasil: construindo o país do futuro. Rio de Janeiro: Elsevier, 2009.

WEST, Anne. School choice, equity and social justice: the case for more control. British Journal of Educational Studies, London, Routledge, v. 54, n. 1, p. 15-33, mar. 2006.

; Pennell, Hazel. How new is the new labour? The quasi-market and english schools 1997-2001. British Journal of Educational Studies, London, Routledge, v. 50, n. 2, p. 206-224, 2002.

YAIR, Gad. School organization and market ecology: a realist sociological look at the infrastructure of school choice. British Journal of Sociology of Education, London, Routledge, v. 17, n. 4, p. 453-471, 1996.

Zanten, Agnès van. Choisir son école. Stratégies familiales et médiations locales. Paris: Presses Universitaires de France, 2009.

\section{SOBRE OS AUTORES}

Ana Lorena Bruelé doutoranda em educação pela Universidade Federal do Rio de Janeiro (UFRJ).

E-mail: analorena.bruel@gmail.com 
Tiago Lisboa Bartholo é doutorando em educação pela Universidade Federal do Rio de Janeiro (UFRJ).

E-mail: tiagobartholo@gmail.com

Recebido em agosto de 2011 Aprovado em outubro de 2011 


\section{ANA LORENA BRUEL E TIAGO LISBOA BARTHOLO}

\section{Desigualdade de oportunidades educacionais na rede pública municipal do Rio de Janeiro: transição entre os segmentos do ensino fundamental}

O estudo analisa os procedimentos de transferência de alunos entre o primeiro e o segundo segmento do ensino fundamental, em escolas públicas comuns da rede municipal da cidade do Rio de Janeiro. Objetiva identificar fatores que condicionam a chance de acesso a escolas que obtiveram bons resultados em avaliações nacionais. Focaliza escolas de dois bairros vizinhos da zona norte da cidade, com grande diversificação entre os estabelecimentos no que diz respeito aos resultados e ao nível socioeconômico da população atendida. O estudo foi desenvolvido com base a partir da análise das trajetórias escolares dos alunos desses estabelecimentos entre 2008 e 2009. Os resultados indicam que a transferência de alunos no período de transição analisado não é aleatória e cria um cenário de homogeneização das escolas investigadas. Os dados sugerem a definição precoce das trajetórias escolares desses alunos nos anos iniciais do ensino fundamental.

Palavras-chave: estratificação escolar; quase mercado oculto; oportunidades educacionais. 


\section{Inequality of educational opportunities in Rio de Janeiro public school system: transition between segments of elementary school}

This study analyses the procedures for students transfer between schools of the first and the second segments of elementary education. It focuses ordinary public schools of Rio de Janeiro City education system. It aims to identify the factors that determine the chances of access to schools with good results in national assessments. It focuses on two neighbor schools located in two nothern neighborhoods of the city with a wide variation in school performance and socioeconomic status. The study analyzed students'school trajectories in 2008 and 2009. Results suggest that student transference in the transition period analyzed did not occur randomly and that it created a scenario of homogenization of the schools surveyed. The data also suggest an early definition of the school trajectories of those students in the early grades of elementary education.

Keywords: school stratification; hidden quasi-market; education opportunities.

\section{Desigualdad de oportunidades educacionales en la red pública municipal de Rio de Janeiro: transición entre los segmentos de la enseñanza básica}

El estudio examina los procedimientos de transferencia de alumnos entre el primery el segundo segmento de la enseñanza básica en escuelas públicas de la red municipal en la ciudad de Rio de Janeiro. Tiene como objetivo identificar los factores que influyen en las posibilidades de acceso a las escuelas que han obtenido buenos resultados en las evaluaciones nacionales. El estudio se centra en escuelas de dos barrios vecinos en la zona norte de la ciudad, con una gran diferencia entre las instituciones en lo que se refiere a los resultados y al nivel socioeconómico de la población atendida. El estudio se desarrolló a partir del análisis de las trayectorias de los estudiantes en estas escuelas entre 2008 y 2009. Los resultados muestran que la transferencia de alumnos en el periodo de transición examinado no es aleatoria y crea un escenario de homogeneización de las escuelas investigadas. Los datos sugieren la definición precoz de las trayectorias escolares de esos alumnos en los primeros años de la enseñanza básica.

Palabrasclave: estratificación escolar; casi mercado oculto; oportunidades educacionales. 